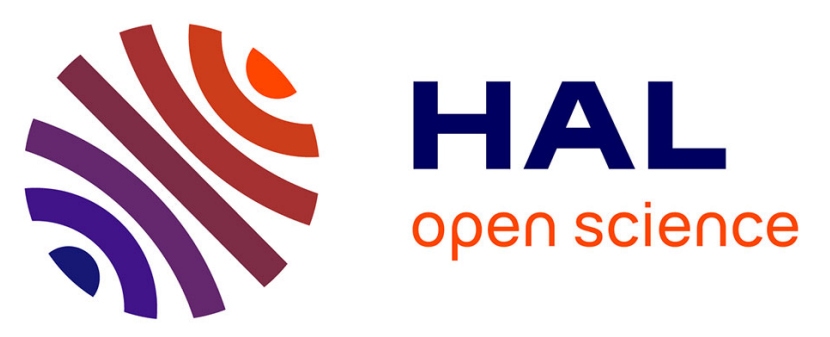

\title{
Placental volume and other first-trimester outcomes: are there differences between fresh embryo transfer, frozen-thawed embryo transfer and natural conception?
}

Cécile Choux, Perrine Ginod, Julie Barberet, Thierry Rousseau, Céline Bruno, Paul Sagot, Karine Astruc, Patricia Fauque

\section{To cite this version:}

Cécile Choux, Perrine Ginod, Julie Barberet, Thierry Rousseau, Céline Bruno, et al.. Placental volume and other first-trimester outcomes: are there differences between fresh embryo transfer, frozen-thawed embryo transfer and natural conception?. Reproductive BioMedicine Online, 2019, 38, pp.538 - 548. 10.1016/j.rbmo.2018.12.023 . hal-03486390

\section{HAL Id: hal-03486390 \\ https://hal.science/hal-03486390}

Submitted on 20 Dec 2021

HAL is a multi-disciplinary open access archive for the deposit and dissemination of scientific research documents, whether they are published or not. The documents may come from teaching and research institutions in France or abroad, or from public or private research centers.
L'archive ouverte pluridisciplinaire HAL, est destinée au dépôt et à la diffusion de documents scientifiques de niveau recherche, publiés ou non, émanant des établissements d'enseignement et de recherche français ou étrangers, des laboratoires publics ou privés.

\section{(c) (1) $\$$}

Distributed under a Creative Commons Attribution - NonCommerciall 4.0 International 


\section{Placental volume and other first-trimester outcomes: are there differences between} fresh embryo transfer, frozen-thawed embryo transfer and natural conception?

Cécile Choux ${ }^{a,{ }^{*}}$, Perrine Ginod ${ }^{a}$, Julie Barberet ${ }^{b}$, Thierry Rousseau ${ }^{a}$, Céline Bruno ${ }^{b}$, Paul Sagot ${ }^{a}$, Karine Astruc ${ }^{c}$, Patricia Fauque ${ }^{b}$

${ }^{\text {a }}$ Dijon University Hospital, Fetal Health and Infertility Department, F-21000 Dijon, France

${ }^{\mathrm{b}}$ Dijon University Hospital, Reproductive Biology Department , F-21000 Dijon, France

${ }^{c}$ Dijon University Hospital, Epidemiology Unit, F-21000 Dijon, France

\section{${ }^{*}$ Corresponding author}

Dr Cécile Choux, MD

Service de Gynécologie-Obstétrique et Biologie de la Reproduction

CHU Dijon - BP 77908

14, rue Paul Gaffarel

21079 Dijon Cedex, France

Tel (Office): +333-80-29-50-31

Tel (Lab): +333-80-29-51-01

Fax: +333-80-29-51-16

cecile.choux@chu-dijon.fr

\section{Declarations of interest: None}




\section{ABSTRACT}

Research question: Does the mode of conception influence placental volume and other first-trimester outcomes?

Design: This retrospective single-centre case-control study led in Dijon University Hospital included 252 singleton pregnancies (84 in vitro fertilization [IVF] with either fresh embryo transfer [fresh ET] or frozen-thawed embryo transfer [FET] and 168 natural conceptions). First-trimester placental volume, uterine artery pulsatility index and maternal serum PAPP-A and $\beta$-hCG were measured. Statistical analyses were adjusted for gestational age, the newborn's gender, maternal age, parity, body mass index and smoking status.

Results: Placental volume was significantly greater in the FET group than in control $(P=$ $0.043)$ and fresh ET $(P=0.023)$ groups. At birth, fresh ET new-borns were significantly smaller than controls $(P=0.01)$ and FET new-borns $(P=0.008)$. Post-partum haemorrhage was far more frequent in FET than in controls and fresh ET group $(38.1 \%, 2.6 \%$ and $1.9 \%$, respectively; $P<0.0001$ ). Placental volume positively correlated with PAPP-A, $\beta-h C G$ and the new-born's birth weight, and negatively correlated with uterine artery pulsatility index. Conclusions: Placental volume and other first-trimester parameters are modified by IVF with fresh ET and FET as compared with natural conception, but with opposite trends. Given the different protocols used for these techniques, hormonal treatment per se may have a major impact on pregnancy outcomes through the modification of placental invasiveness.

\section{Key message}

Placental volume and other first-trimester outcomes are modified by IVF with fresh embryo transfer and frozen-thawed embryo transfer with opposite trends. Hormonal treatment may influence pregnancy outcomes through the modification of placental invasiveness. The origins of these variations have to be deciphered and minimized to avoid maternal and foetal morbidity. 


\section{Keywords}

fresh embryo transfer, frozen-thawed embryo transfer, in vitro fertilization, placenta, placental volume, first-trimester pregnancy

\section{INTRODUCTION}

It is estimated that more than five million children have been born by Assisted Reproductive Technologies (ART) worldwide, representing up to 4\% of all births (Messerlian and Gaskins, 2017), and there is an increasing number of initiated cycles from year to year (Dyer et al., 2016). Between 8 and 12\% of reproductive-aged couples are currently infertile (Vander Borght and Wyns, 2018), and providing them with safe techniques to achieve parenthood is a public health issue. However, the safety of these techniques has not been fully demonstrated. Notably, the rate of placenta-related adverse pregnancy outcomes such as miscarriages, preeclampsia, placenta praevia, placenta accreta and placental abruption could be increased after ART (Thomopoulos et al., 2013). Adverse perinatal outcomes such as small for gestational age (SGA) or large for gestational age (LGA) have also been reported after fresh and frozen-thawed embryo transfer, respectively, even in singleton pregnancies (Pinborg et al., 2014; Weinerman and Mainigi, 2014). Our team and others have suggested that these conditions could be linked to inadequate trophoblastic invasion of uterine decidua and spiral arteries during early pregnancy (Prefumo et al., 2007; Choux et al., 2015).

In mammals, the placenta is a pregnancy-specific temporary organ that creates intimate contact between mother and foetus to ensure the maintenance of gestation and foetal well-being by the exchange of gases, nutrients and waste products (Zhang et al., 2008). Its formation involves a molecular crosstalk between the maternal endometrium and the peripheral multipotent cells of the blastocyst called trophoblasts (Chelbi and Vaiman, 2008). This finely-tuned temporal and spatial regulation of trophoblastic invasion, essential for proper future functions of the placenta and foetal development, may be disrupted by ART (Chelbi and Vaiman, 2008; Denomme and Mann, 2012; Choux et al., 2015). Given the 
statements of the Developmental Origin of Health and Diseases (DOHaD) concept (Barker et al., 1990), disturbed maternal-foetal interactions could not only have consequences for outcomes in childhood but also in adulthood (Gillman, 2005; Isles and Holland, 2005; Nathanielsz, 2006; Barker, 2007; Gluckman et al., 2008; Reynolds and Caton, 2012; Vrooman and Bartolomei, 2017).

Thus, as placental and foetal growth are closely linked and given the increased incidence of placenta-related adverse outcomes after ART and their potential long-term consequences, studying the placenta in the context of ART is of particular interest. A previous large cohort study reported lower birth weight and higher placental weight after IVF, ICSI or other methods of ART (Haavaldsen et al., 2012). Additionally, in animal models, many placental modifications have been reported after ART throughout pregnancy (Miles et al., 2004; Miles et al., 2005; Giritharan et al., 2007; Delle Piane et al., 2010; Fauque et al., 2010; Fauque et al., 2010; Bloise et al., 2012; Ptak et al., 2013).

Because placental weight cannot be assessed during pregnancy in humans, 3Dultrasound has brought dramatic progress in the last decade by making it easy to measure placental volume (PV) (Wegrzyn et al., 2005; Cheong et al., 2010; Rizzo et al., 2015). Several authors have investigated the relationships between first-trimester PV and adverse obstetric outcomes. PV has been shown to be predictive of preeclampsia (Rizzo et al., 2008; Arakaki et al., 2015; Yucel et al., 2016), associated with birth weight below the $10^{\text {th }}$ percentile (Effendi et al., 2014; Schwartz et al., 2014; Gonzalez-Gonzalez et al., 2017), strongly correlated with birth weight and placental weight at birth (Effendi et al., 2014) and even predictive of placental insufficiency-related complications (Papastefanou et al., 2018). Despite the data, few studies have investigated PV after in vitro fertilization (IVF), and their results were conflicting (Rifouna et al., 2014; Rizzo et al., 2015; Churchill et al., 2017; Sundheimer et al., 2018). Indeed, some studies found no significant difference in PV between IVF and spontaneous pregnancies at 10 WG (Rifouna et al., 2014) or at 12 WG (Churchill et al., 2017; Sundheimer et al., 2018), while Rizzo et al. (Rizzo et al., 2015) evidenced significantly reduced PV in IVF pregnancies. Only one other study distinguished 
IVF after fresh embryo transfer (fresh ET) from those after frozen-thawed embryo transfer (FET) (Rizzo et al., 2016), but without providing a full vision of first-trimester markers and their relationship with perinatal and obstetrical outcomes. Yet, some first-trimester parameters have been associated with adverse pregnancy outcomes. For example, low levels of PAPP-A and beta-hCG in first-trimester maternal serum, high uterine PI and/or notching in the waveform of uterine artery Doppler could be associated with low birth weight (Shwarzman et al., 2013; Zhu et al., 2015; Gundu et al., 2016; Sirikunalai et al., 2016; Stampalija et al., 2017) and first-trimester CRL could correlate positively with birthweight (Hackmon et al., 2017). Currently, PAPP-A and uterine artery PI are even recognized to be predictive of placenta-related diseases such as preeclampsia (Tan et al., 2018) and small for gestational age (Tan et al., 2018).

The primary endpoint of this single-centre cohort study was to compare PV between 11 weeks of gestation (WG) and $13 \mathrm{WG}+6$ days according to different modes of conception: natural, IVF with fresh ET and IVF with FET. The secondary endpoints were comparisons between groups for crown-rump length $(\mathrm{CRL})$, uterine artery pulsatility index $(\mathrm{PI})$, incidence of notching, and maternal serum markers values (PAPP-A and $\beta-h C G)$. 


\section{MATERIALS AND METHODS}

\section{Study population}

This retrospective single-centre study included all singleton pregnancies after IVF with fresh ET or FET, with dates of pregnancy between 01/10/2013 and 31/01/2015, followed at the Dijon University Hospital for the first trimester ultrasound (11 WG -13 WG +6 days), and with available 3D placental acquisition. Exclusion criteria were: presence of pre-existing maternal diseases (diabetes, chronic hypertension), oocyte donation, foetal malformation or abnormal karyotype. For each patient, two controls fulfilling the same criteria were randomly selected during this period of time from our computerised database.

Women from the fresh ET group underwent ovarian stimulation, where ovulation was triggered by recombinant hCG. Fertilization was achieved either by conventional IVF or by Intra Cytoplasmic Sperm Injection (ICSI). Depending on the woman's age, the number of previous cycles and the number and quality of available embryos, one to three fresh embryos were transferred at day 2, 3 or 5 after oocyte retrieval, $86.7 \%$ being transferred at day 2 or 3 . Patients were given $400 \mathrm{mg}$ of progesterone per day vaginally from the day after oocyte retrieval until 6 WG and thereafter $200 \mathrm{mg}$ per day until 8 WG. In accordance with the French National College of Obstetrics and Gynaecology, the date of pregnancy was the date of oocyte retrieval (Salomon, 2011).

The FET group included patients who were conditioned by a sequential two phase protocol. The first phase starts on day 2 of the menstrual cycle and uses oestrogens alone (2 $\mathrm{mg}$ estradiol per day for three days followed by $4 \mathrm{mg}$ per day for three days and then $6 \mathrm{mg}$ per day until the embryo transfer). The second phase includes oestrogens ( $6 \mathrm{mg}$ per day and then $8 \mathrm{mg}$ per day if the pregnancy test is positive) and intravaginal progesterone (400 $\mathrm{mg}$ per day from 2, 3 or 5 days before the transfer of day-2, -3 or -5 frozen embryos, respectively, then $600 \mathrm{mg}$ per day after the transfer and $800 \mathrm{mg}$ per day if the pregnancy test is positive) until 12 WG. Embryo cryopreservation is done on day 2, 3 or 5 , and frozenthawed embryo transfers were performed as previously described (Desch et al., 2017), $83.3 \%$ of embryos being transferred at day 2 or 3 . In accordance with fresh ET group, the 
date of pregnancy for FET group was calculated as follows: date of the transfer minus the number of days of embryo culture.

\section{Ultrasound data}

All ultrasound scans were performed transabdominally between $11 \mathrm{WG}$ and $13 \mathrm{WG}+$ 6 days, with the same apparatus (Voluson E8, GE Medical Systems, Milwaukee, WI, USA) in the prenatal diagnosis department (Dijon University Hospital, France) by staff skilled in antenatal diagnosis. Natural pregnancies were dated as recommended by measuring CRL (Salomon, 2011). In accordance with Papageorghiou et al. (Papageorghiou et al., 2014), the formulae were:

$\mathrm{CRL}=-50.6562+(0.815118 \times \mathrm{GA})+\left(0.00535302 \times \mathrm{GA}^{2}\right)(\mathrm{GA}$ is the gestational age [days] $)$

SD CRL $=-2.21626+(0.0984894 \times \mathrm{GA})(S D$ is the standard deviation $)$

$\mathrm{GA}=40.9041+\left(3.21585 \times \mathrm{CRL}^{0.5}\right)+(0.348956 \times \mathrm{CRL})$

$\mathrm{SD} G A=2.39102+(0.0193474 \times \mathrm{CRL})$

To measure placental volume, Virtual Organ Computer-aided AnaLysis (VOCAL II GE Medical Systems, Milwaukee, WI, USA) with a rotation angle of $15^{\circ}$ is the most precise and reproducible technique (Wegrzyn et al., 2005; Cheong et al., 2010; Rizzo et al., 2015; Papastefanou et al., 2018). In our centre, 3D placental volume was acquired routinely according to standardized protocol with a sweep angle set at $85^{\circ}$ and a volume box set so as to include the whole placenta. Subsequent volume analyses were performed later by the same observer, blinded to the method of conception and pregnancy outcomes. Placental shape was drawn manually in 12 sections, using a rotation angle of $15^{\circ}$. The volume was then calculated by computer. Each volume was measured twice and the mean was used for analyses. If the variation was greater than $5 \mathrm{~cm}^{3}$, measurements were repeated. The uterine artery PI was measured on the right and left arteries. Maximal PI was collected for analysis. $\mathrm{PI}$ is defined as $\mathrm{PI}=(\mathrm{S}-\mathrm{D}) / \mathrm{m}$, where $\mathrm{S}$ is maximal velocity during systole, $\mathrm{D}$ is minimal velocity during diastole and $m$ is mean velocity. Maternal serum PAPP-A and $\beta$-hCG values 
were measured the same day as the first-trimester ultrasound in the Dijon University hospital laboratory and expressed in multiple of the median (MoM).

\section{Clinical data and definitions}

Maternal and ART data were extracted from our prospective database and clinical records were consulted in case of missing or inconsistent data. CRL was expressed as zscores, calculated as follows: $z$-score $=(C R L$ observed - mean $C R L$ for $G A) /(S D C R L)$, in accordance with Papageorghiou et al. (Papageorghiou et al., 2014). Concerning birth weight, the z-score was calculated according to our 2008 Burgundy population growth curves further adjusted in 2011 for new-born gender (Rousseau et al., 2008). Using these curves, SGA and LGA were defined as birth weight $<10^{\text {th }}$ and $>90^{\text {th }}$ percentile, respectively (Rousseau et al., 2008). Gestational hypertension (GH) was defined as systolic blood pressure (BP) $\geq 140$ $\mathrm{mmHg}$ and/or diastolic $\mathrm{BP} \geq 90 \mathrm{mmHg}$. Preeclampsia was the association of $\mathrm{GH}$ and proteinuria $>0.3 \mathrm{~g} / 24$ hours after 20 WG. Gestational diabetes mellitus was diagnosed according to guidelines of National College of Obstetrics and Gynecology, either if firsttrimester fasting glucose $\geq 0.92 \mathrm{~g} / \mathrm{L}$ or if any of the following cut-offs for the $75 \mathrm{~g}$ oral glucose tolerance test (performed between 24 and 28 WG) was met: fasting glucose $\geq 0.92$, 1-hour $\geq$ $1.80,2$-hour $\geq 1.53 \mathrm{~g} / \mathrm{L}$ (CNGOF, 2010). Post-partum haemorrhage (PPH) was defined as blood loss $>500 \mathrm{~mL}$ within 24 hours after delivery, regardless of the route of delivery, according to recent guidelines (Sentilhes et al., 2016).

\section{Statistical analyses}

Categorical variables were expressed as numbers (percentages) and compared using the Chi-2 test or Fisher exact test when appropriate. Continuous variables were expressed as mean \pm SD and compared using ANOVA when more than two groups or with Student's or the Mann-Whitney test, as appropriate. To compare the three groups, global tests were first used and if they resulted in $\mathrm{P}<0.05$, then each ART group was compared to the controls. Multivariate analyses were performed using multiple regression linear models. 
Maternal age, height, weight, body mass index (BMI), parity, smoking habits, gestational age and sex of the new born, when associated with the dependent variable resulting in a P-value below 0.2 in bivariate analyses, were included in the multiple regression analysis. Indeed, as placental weight at birth can be modified by these factors (Ouyang et al., 2016), we considered that first-trimester PV could also be affected. A Shapiro-Wilk test was performed for the normality of quantitative variables. When rejected, log-transformation of the variable distribution was tested. Because the distribution of PV was not normal, logarithmic transformation was done. Seeing as placental volume is dependent on GA, all analyses were adjusted for GA. The linear form of continuous variables was checked by means of fractional polynomials.

All statistical analyses were performed with Stata software, version 10 (Stata corporation, College Station TX, USA). The tests were two-tailed, and a P-value below 0.05 was considered statistically significant.

\section{Ethics Statement}

Our study is a human non-interventional study where subjects were not assigned to treatment. Epidemiological methods were used to analyze the data, and information used in the study was collected for clinical care. According to the French Public Health Law, approval from the Institutional Review Board and written consent are not required for noninterventional human studies. However, formal confirmation that ethical approval was not required for this observational study was obtained. 


\section{RESULTS}

\section{Population characteristics}

A total of 84 singleton ART pregnancies ( 60 fresh ET [13 conventional IVF and 47 IVF with ICSI], 24 FET [9 conventional IVF and 15 IVF with ICSI]) and 168 singleton controls were included in this study.

Demographic and clinical characteristics of the pregnancies studied are summarized in Table 1. Notably, ART mothers were different from controls in terms of age, smoking habits and parity. ART mothers were older than controls. Tobacco smoking was more frequent in controls than fresh ET. Parity was lower in the fresh ET group than in controls and FET but was the same in controls and the FET group.

\section{First-trimester Data}

As recommended, natural pregnancies were dated by measuring the $C R L$ and using the curve of Papageorghiou et al. (Papageorghiou et al., 2014), so their z-score of CRL is 0. No difference was observed when comparing the FET and fresh ET groups to this curve or by comparing one group to the other (Figure 1A; Table 2).

After adjustments for gestational age and maternal height, log PV was significantly greater in the FET group $\left(4.52 \pm 0.39 \mathrm{~cm}^{3}\right)$ than in the control group $\left(4.40 \pm 0.28 \mathrm{~cm}^{3} ; \mathrm{P}=\right.$ $0.043)$ and in the fresh ET group $\left(4.38 \pm 0.37 \mathrm{~cm}^{3} ; \mathrm{P}=0.024\right.$, Figure $\left.1 \mathrm{~B}\right)$.

PI was significantly higher in the fresh ET group $(1.86 \pm 0.64)$ than in controls $(1.52 \pm$ 0.59; $P=0.001$; Table 2), even after adjustments for gestational age $(P=0.001$; Figure $1 C)$. Conversely, PI was lower in the FET group $(1.26 \pm 0.44)$ than in the fresh ET group $(P=$ 0.001 ; Table 2), even after adjustment on gestational age ( $P=0.001$, Figure $1 \mathrm{C})$. $\mathrm{PI}$ was also lower in the FET group than in controls, but the difference was not significant.

Consistently, diastolic notching was more frequent in fresh ET patients $(55.6 \%)$ than controls $(32.5 \%, P=0.003$; Table 2$)$, even after adjusting for the sex of the new-born, 
maternal age and parity $(P=0.016)$, whereas the incidence of diastolic notching was similar between FET and controls (Table 2).

Maternal serum markers were significantly lower in the fresh ET group than in controls: $0.91 \pm 0.48$ vs. $1.12 \pm 0.60(\mathrm{P}=0.016)$ for PAPP-A and $0.92 \pm 0.47$ vs. $1.21 \pm 0.67$ for $\beta$-hCG (P = 0.002; Table 2).

\section{Obstetrical and neonatal outcomes}

When comparing the obstetrical and neonatal outcomes between groups, ART patients were not different from controls except for $\mathrm{PPH}$, instrumental delivery and birth weight (Table 3). In fact, the incidence of instrumental delivery was no different between the studied groups after adjusting for parity $(P=0.325)$. Even after adjusting for birth weight, maternal age, parity and the occurrence of C-section, $\mathrm{PPH}$ remained significantly more frequent in the FET group than in the control group $(38.1 \%$ vs. $2.6 \%, P=0.003)$ and in the IVF group $(1.9 \%, P=0.021)$, whereas the incidence of $\mathrm{PPH}$ was similar in the fresh ET group and controls $(P=0.861)$. In the FET group, $\mathrm{PPH}$ was due to retained placenta or retained placental fragments requiring manual removal $(n=4$, including one placenta accreta), and during $\mathrm{C}$-section $(\mathrm{n}=4)$. Of note, there was no correlation between the risks of $\mathrm{PPH}$ and the new-born's birth weight or the incidence of C-section.

After adjusting for BMI, tobacco smoking and parity, the z-score for birth weight remained significantly lower in the fresh ET group $(-0.60 \pm 0.96)$ than in the control group ($0.07 \pm 0.92 ; P=0.010)$ and in the FET group $(0.15 \pm 1.27 ; P=0.008 ;$ Figure $1 D)$.

\section{PV correlations}

After adjusting for gestational age, log PV was positively associated with maternal serum $\beta$-hCG ( $r$-squared for regression model: $r^{2}=0.15$, linear regression coefficient: $\beta=$ $0.09, P=0.006)$ and maternal serum PAPP-A $\left(r^{2}=0.18, \beta=0.13, P<0.0001\right)$, and negatively associated with uterine artery $\mathrm{PI}\left(\mathrm{r}^{2}=0.16, \beta=-0.09, \mathrm{P}=0.004\right.$; Supplemental 
Figure $1 \mathrm{~A}, \mathrm{~B}$ and $\mathrm{C}$, respectively). Notably, the correlation between PAPP-A and log PV was stronger for the FET group $\left(r^{2}=0.62, \beta=0.37, P<0.0001\right.$; Supplemental Figure 1D).

The z-score for birth weight correlated positively with first-trimester maternal serum PAPP-A $\left(r^{2}=0.12, \beta=0.57, P<0.0001\right.$; Supplemental Figure $\left.2 A\right)$, with log $P V\left(r^{2}=0.03, \beta=\right.$ $0.51, \mathrm{P}=0.022$; Supplemental Figure $2 \mathrm{~B}$ ), inversely with the presence of unilateral or bilateral notching of uterine artery $\left(r^{2}=0.03, \beta=-0.37, P=0.012\right)$ and did not correlated with $\beta$-hCG and PI $(P>0.05)$. 


\section{DISCUSSION}

With an original design providing a global vision of first-trimester data and robust methodology, our study gives novel insights about placental function and its link with pregnancy outcomes. We found increased first-trimester placental volume after FET compared to controls and fresh ET, suggesting that ART has an impact on placental development.

Data in the literature about placental growth throughout pregnancy following ART are conflicting. A study comparing IVF with natural pregnancies found a significantly smaller firsttrimester PV in the IVF group, and even smaller PV in the oocyte-donor subgroup (Rizzo et al., 2015). On the contrary, Rifouna et al. (Rifouna et al., 2014) and two other studies (Churchill et al., 2017; Sundheimer et al., 2018) compared trophoblastic volumes at $10 \mathrm{WG}$ and around 12 WG, respectively, and did not find any significant difference. In the three studies, the IVF group included patients who indistinctly received fresh or frozen-thawed embryos, but because of the major differences between the protocols, especially the additional freezing-thawing step and different hormonal stimulation used for FET, it is hardly conceivable to group them together. Like ours, another study found larger PV in pregnancies after FET compared with pregnancies after fresh ET (Rizzo et al., 2016). As PV correlated with birth weight, this is consistent with the findings of a higher incidence of LGA new-borns after FET (Pinborg et al., 2014; Spijkers et al., 2017).

Interestingly, in addition to the study of PV, our work also provides a full vision of firsttrimester data and the associated obstetrical significance, and helps to decipher the differences in trophoblastic invasion according to the mode of conception. PAPP-A contributes to maternal tolerance towards the foetus (Zhabin et al., 2003) and is considered as an early marker of trophoblastic invasion (Fournier et al., 2008). The level of maternal serum first-trimester PAPP-A, as in our study, was found to positively correlate with birth weight (David and Jauniaux, 2016) and be associated with low birth weight and preeclampsia if low (Zhu et al., 2015; Gundu et al., 2016), and LGA if high (David and Jauniaux, 2016). 
Produced by trophoblastic cells, hCG promotes the invasion of cytotrophoblasts and supports foetal and placental growth (Cole, 2010), making consistent our finding of its correlation with PV. Increased uterine artery $\mathrm{PI}$ is the expression of increased vascular resistances, which corrupt endovascular trophoblastic invasion (Prefumo et al., 2004; Prefumo et al., 2007), consistently with the negative correlation between PV and PI observed in the present study and in others (Hashish et al., 2015). Overall, PV correlated with these three markers, which supports the hypothesis that PV could be a surrogate marker of trophoblastic invasiveness.

Altogether, by analysing the comprehensive "first-trimester overview" given by these markers, we observed interesting opposing trends between fresh ET and FET (Figure 2), suggesting insufficient or excessive placental invasion, respectively. Insufficient placental invasion after fresh ET is witnessed in our study and/or others by lower maternal hCG (Hui et al., 2005) and PAPP-A levels (Hui et al., 2005; Tul and Novak-Antolic, 2006; Anckaert et al., 2008; Gjerris et al., 2009; Cavoretto et al., 2017; Hunt et al., 2017), lower PV (Rizzo et al., 2016), higher PI and lower birth weight (Jackson et al., 2004) than natural pregnancies and increased frequency of abruptio placentae (Healy et al., 2010) and preeclampsia (Imudia et al., 2013). On the contrary, excessive placental invasion in FET is visible in our study and/or others through increased PV, increased maternal hCG (Hui et al., 2003), higher risk of manual placental extraction (Aziz et al., 2016), placenta accreta (Kaser et al., 2015; Ata and Seli, 2017), and PPH (Healy et al., 2010) due to the absence of spontaneous delivery of the placenta and higher frequency of LGA (Pinborg et al., 2014; Spijkers et al., 2017). It suggests that a first-trimester evaluation for trophoblastic invasion combining all these markers would be highly valuable in ART pregnancies. Patients presenting with either an increase or a decrease in placental invasion could thus benefit from closer follow-up, particularly for foetal growth and for the risk of PPH during delivery.

In addition to the measures for prevention to set up, these data raise the question of the origin of the differences between FET and fresh ET. Two points stand out: 1-the additional freezing-thawing step in FET; and 2- the different hormonal stimulation used 
between the two techniques. The freezing-thawing step could modify the developmental potential of the embryos and thus the obstetrical outcomes (Spijkers et al., 2017). However, it is now largely recognized that endometrium-embryo synchrony is essential in IVF. Indeed, the duration of the window of implantation, defined by the perfect balance of oestradiol and progesterone, may only last 2 to 5 days (Ozgur et al., 2018). Progesterone in particular has to be tightly regulated to ensure the highest rates of implantation. For example, the optimal mid-luteal progesterone concentration is thought to be $80-100 \mathrm{nmol} / \mathrm{L}$ for stimulated cycles (Yding Andersen and Vilbour Andersen, 2014) and 70-99 nmol/L in FET cycles (Yovich et al., 2015). In addition, there is now converging evidence suggesting that hormonal therapy could affect endometrial receptivity, thus trophoblastic invasion and finally pregnancy outcomes. A high dose of total FSH negatively impacted live birth rates in fresh ET compared to subsequent FET (Munch et al., 2017). Increased oestrogen levels at ovulation triggering before fresh ET were associated with lower first-trimester PAPP-A levels, preeclampsia, low birth-weight and preterm birth (Imudia et al., 2012; Giorgetti et al., 2013; Hu et al., 2014; Liu et al., 2017). PAPP-A values were found to be lower after fresh ET than after FET (Amor et al., 2009; Gjerris et al., 2009). In the same line as our results, FET in artificial cycles was associated with increased PPH risk compared with FET in natural cycles (Healy et al., 2010; Nakamura et al., 2015). The use of hCG triggering or progesterone supplementation for FET has been associated with lower clinical pregnancy rates than FET after natural cycles (Montagut et al., 2016). Particularly, micronized progesterone has been shown to increase placental volume if given in first trimester threatened abortion (Turgal et al., 2017). In our centre, the different conditioning between fresh ET and FET patients result in a cumulated dose of progesterone nearly 4 times lower for fresh ET, but in this case, the proper secretion of hormones by the multiple corpus lutea also has to be taken into account (Conrad and Baker, 2013).

The main strengths of our study, which was conducted in a single-centre, lie in its homogeneous population, well-standardized protocols and the good quality ultrasound measurements ensured by our highly skilled staff. In addition, all results were adjusted for 
many potential confounding factors such as maternal age or parity. One weakness is the small number of patients, but the accuracy of our conclusions is ensured by the robust design and the comprehensive data collection, making our results consistent with most data in the literature. In order to ensure the homogeneity of the cohort and treatments used, we chose to lead a monocentric study, but it would be worthwhile for future studies to validate the results found here in other ART centres. Another limitation is the absence of data about the kinetics of placental and foetal growth. Indeed, crucial events for placental invasion are already completed before 12 WG (Moser and Huppertz, 2017), so it would be valuable to study the embryo from the very beginning of pregnancy, although the small size before 11 WG would limit the accuracy of measurements. Otherwise, by the end of pregnancy, the plasticity of placenta can still change the whole picture of it (Choux et al., 2015), so late measures would be useful too, although measuring a larger placenta would also be technically difficult.

To conclude, ART can modify the delicate implantation step. Considering the potential effects of hormonal therapy on foeto-placental growth and even adverse outcomes such as $\mathrm{PPH}$, we have to decipher the origin of these variations and strive to minimize them in order to avoid maternal and foetal morbidity, for example by reconsidering treatments for conditioning women before FET, with the aim of obtaining implantation similar to natural pregnancy.

\section{ACKNOWLEDGEMENTS}

The authors thank Philip Bastable and Suzanne Rankin for improving the English language and the midwives of Dijon University Hospital for participating in the study (Isabelle Hance, Fany Bobert, Danyèle Gagnaux, Régine Choiseau, Cécile Bouillot, Fabienne Andres, Christelle Koffmann, Laurence Bernard). 


\section{FUNDING}

This research did not receive any specific grant from funding agencies in the public, commercial, or not-for-profit sectors. 


\section{REFERENCES}

Amor, D.J., Xu, J.X., Halliday, J.L., Francis, I., Healy, D.L., Breheny, S., Baker, H.W. and Jaques, A.M., 2009. Pregnancies conceived using assisted reproductive technologies (ART) have low levels of pregnancy-associated plasma protein-A (PAPP-A) leading to a high rate of false-positive results in first trimester screening for Down syndrome. Hum Reprod. 24, 1330-1338.

Anckaert, E., Schiettecatte, J., Sleurs, E., Devroey, P. and Smitz, J., 2008. First trimester screening for Down's syndrome after assisted reproductive technology: non-male factor infertility is associated with elevated free beta-human chorionic gonadotropin levels at 10-14 weeks of gestation. Fertil Steril. 90, 1206-1210.

Arakaki, T., Hasegawa, J., Nakamura, M., Hamada, S., Muramoto, M., Takita, H., Ichizuka, K. and Sekizawa, A., 2015. Prediction of early- and late-onset pregnancy-induced hypertension using placental volume on three-dimensional ultrasound and uterine artery Doppler. Ultrasound Obstet Gynecol. 45, 539-543.

Ata, B. and Seli, E., 2017. A universal freeze all strategy: why it is not warranted. Curr Opin Obstet Gynecol. 29, 136-145.

Aziz, M.M., Guirguis, G., Maratto, S., Benito, C. and Forman, E.J., 2016. Is there an association between assisted reproductive technologies and time and complications of the third stage of labor? Arch Gynecol Obstet. 293, 1193-1196.

Barker, D.J., 2007. The origins of the developmental origins theory. J Intern Med. 261, 412417.

Barker, D.J., Bull, A.R., Osmond, C. and Simmonds, S.J., 1990. Fetal and placental size and risk of hypertension in adult life. BMJ. 301, 259-262.

Bloise, E., Lin, W., Liu, X., Simbulan, R., Kolahi, K.S., Petraglia, F., Maltepe, E., Donjacour, A. and Rinaudo, P., 2012. Impaired placental nutrient transport in mice generated by in vitro fertilization. Endocrinology. 153, 3457-3467.

Cavoretto, P., Giorgione, V., Cipriani, S., Vigano, P., Candiani, M., Inversetti, A., Ricci, E. and Parazzini, F., 2017. Nuchal translucency measurement, free beta-hCG and PAPP-A concentrations in IVF/ICSI pregnancies: systematic review and metaanalysis. Prenat Diagn. 37, 540-555.

Chelbi, S.T. and Vaiman, D., 2008. Genetic and epigenetic factors contribute to the onset of preeclampsia. Mol Cell Endocrinol. 282, 120-129.

Cheong, K.B., Leung, K.Y., Li, T.K., Chan, H.Y., Lee, Y.P. and Tang, M.H., 2010. Comparison of inter- and intraobserver agreement and reliability between three different types of placental volume measurement technique (XI VOCAL, VOCAL and multiplanar) and validity in the in-vitro setting. Ultrasound Obstet Gynecol. 36, 210217.

Choux, C., Carmignac, V., Bruno, C., Sagot, P., Vaiman, D. and Fauque, P., 2015. The placenta: phenotypic and epigenetic modifications induced by Assisted Reproductive Technologies throughout pregnancy. Clin Epigenetics. 7, 87.

Churchill, S.J., Wang, E.T., Akhlaghpour, M., Goldstein, E.H., Eschevarria, D., Greene, N., Macer, M., Zore, T., Williams, J., 3rd and Pisarska, M.D., 2017. Mode of conception does not appear to affect placental volume in the first trimester. Fertil Steril. 107, 1341-1347 e1341.

Cngof, 2010. [Gestational diabetes]. J Gynecol Obstet Biol Reprod (Paris). 39, S139, S338142.

Cole, L.A., 2010. Biological functions of hCG and hCG-related molecules. Reprod Biol Endocrinol. 8, 102.

Conrad, K.P. and Baker, V.L., 2013. Corpus luteal contribution to maternal pregnancy physiology and outcomes in assisted reproductive technologies. Am J Physiol Regul Integr Comp Physiol. 304, R69-72.

David, A.L. and Jauniaux, E., 2016. Ultrasound and endocrinological markers of first trimester placentation and subsequent fetal size. Placenta. 40, 29-33. 
Delle Piane, L., Lin, W., Liu, X., Donjacour, A., Minasi, P., Revelli, A., Maltepe, E. and Rinaudo, P.F., 2010. Effect of the method of conception and embryo transfer procedure on mid-gestation placenta and fetal development in an IVF mouse model. Hum Reprod. 25, 2039-2046.

Denomme, M.M. and Mann, M.R., 2012. Genomic imprints as a model for the analysis of epigenetic stability during assisted reproductive technologies. Reproduction. 144, 393-409.

Desch, L., Bruno, C., Luu, M., Barberet, J., Choux, C., Lamotte, M., Schmutz, E., Sagot, P. and Fauque, P., 2017. Embryo multinucleation at the two-cell stage is an independent predictor of intracytoplasmic sperm injection outcomes. Fertil Steril. 107, 97-103.

Dyer, S., Chambers, G.M., De Mouzon, J., Nygren, K.G., Zegers-Hochschild, F., Mansour, R., Ishihara, O., Banker, M. and Adamson, G.D., 2016. International Committee for Monitoring Assisted Reproductive Technologies world report: Assisted Reproductive Technology 2008, 2009 and 2010. Hum Reprod. 31, 1588-1609.

Effendi, M., Demers, S., Giguere, Y., Forest, J.C., Brassard, N., Girard, M., Gouin, K. and Bujold, E., 2014. Association between first-trimester placental volume and birth weight. Placenta. 35, 99-102.

Fauque, P., Mondon, F., Letourneur, F., Ripoche, M.A., Journot, L., Barbaux, S., Dandolo, L., Patrat, C., Wolf, J.P., Jouannet, P., Jammes, H. and Vaiman, D., 2010. In vitro fertilization and embryo culture strongly impact the placental transcriptome in the mouse model. PLoS One. 5, e9218.

Fauque, P., Ripoche, M.A., Tost, J., Journot, L., Gabory, A., Busato, F., Le Digarcher, A., Mondon, F., Gut, I., Jouannet, P., Vaiman, D., Dandolo, L. and Jammes, H., 2010. Modulation of imprinted gene network in placenta results in normal development of in vitro manipulated mouse embryos. Hum Mol Genet. 19, 1779-1790.

Fournier, T., Handschuh, K., Tsatsaris, V., Guibourdenche, J. and Evain-Brion, D., 2008. Role of nuclear receptors and their ligands in human trophoblast invasion. J Reprod Immunol. 77, 161-170.

Gillman, M.W., 2005. Developmental origins of health and disease. N Engl J Med. 353, 18481850.

Giorgetti, C., Vanden Meerschaut, F., De Roo, C., Saunier, O., Quarello, E., Hairion, D., Penaranda, G., Chabert-Orsini, V. and De Sutter, P., 2013. Multivariate analysis identifies the estradiol level at ovulation triggering as an independent predictor of the first trimester pregnancy-associated plasma protein-A level in IVF/ICSI pregnancies. Hum Reprod. 28, 2636-2642.

Giritharan, G., Talbi, S., Donjacour, A., Di Sebastiano, F., Dobson, A.T. and Rinaudo, P.F., 2007. Effect of in vitro fertilization on gene expression and development of mouse preimplantation embryos. Reproduction. 134, 63-72.

Gjerris, A.C., Loft, A., Pinborg, A., Christiansen, M. and Tabor, A., 2009. First-trimester screening markers are altered in pregnancies conceived after IVF/ICSI. Ultrasound Obstet Gynecol. 33, 8-17.

Gluckman, P.D., Hanson, M.A., Cooper, C. and Thornburg, K.L., 2008. Effect of in utero and early-life conditions on adult health and disease. N Engl J Med. 359, 61-73.

Gonzalez-Gonzalez, N.L., Gonzalez-Davila, E., Gonzalez Marrero, L., Padron, E., Conde, J.R. and Plasencia, W., 2017. Value of placental volume and vascular flow indices as predictors of intrauterine growth retardation. Eur J Obstet Gynecol Reprod Biol. 212, 13-19.

Gundu, S., Kulkarni, M., Gupte, S., Gupte, A., Gambhir, M. and Gambhir, P., 2016. Correlation of first-trimester serum levels of pregnancy-associated plasma protein $A$ with small-for-gestational-age neonates and preterm births. Int J Gynaecol Obstet.

Haavaldsen, C., Tanbo, T. and Eskild, A., 2012. Placental weight in singleton pregnancies with and without assisted reproductive technology: a population study of 536,567 pregnancies. Hum Reprod. 27, 576-582. 
Hackmon, R., Librach, C., Burwick, R., Rodrigues, N., Farine, D. and Berger, H., 2017. Do Early Fetal Measurements and Nuchal Translucency Correlate With Term Birth Weight? J Obstet Gynaecol Can. 39, 750-756.

Hashish, N., Hassan, A., El-Semary, A., Gohar, R. and Youssef, M.A., 2015. Could 3D placental volume and perfusion indices measured at 11-14 weeks predict occurrence of preeclampsia in high-risk pregnant women? J Matern Fetal Neonatal Med. 28, 1094-1098.

Healy, D.L., Breheny, S., Halliday, J., Jaques, A., Rushford, D., Garrett, C., Talbot, J.M. and Baker, H.W., 2010. Prevalence and risk factors for obstetric haemorrhage in 6730 singleton births after assisted reproductive technology in Victoria Australia. Hum Reprod. 25, 265-274.

Hu, X.L., Feng, C., Lin, X.H., Zhong, Z.X., Zhu, Y.M., Lv, P.P., Lv, M., Meng, Y., Zhang, D., Lu, X.E., Jin, F., Sheng, J.Z., Xu, J. and Huang, H.F., 2014. High maternal serum estradiol environment in the first trimester is associated with the increased risk of small-for-gestational-age birth. J Clin Endocrinol Metab. 99, 2217-2224.

Hui, P.W., Lam, Y.H., Tang, M.H., Ng, E.H., Yeung, W.S. and Ho, P.C., 2005. Maternal serum pregnancy-associated plasma protein-A and free beta-human chorionic gonadotrophin in pregnancies conceived with fresh and frozen-thawed embryos from in vitro fertilization and intracytoplasmic sperm injection. Prenat Diagn. 25, 390-393.

Hui, P.W., Tang, M.H., Lam, Y.H., Ng, E.H., Yeung, W.S. and Ho, P.C., 2003. Maternal serum hCG and alpha-fetoprotein levels in pregnancies conceived after IVF or ICSI with fresh and frozen-thawed embryos. Hum Reprod. 18, 572-575.

Hunt, L.P., Mcinerney-Leo, A.M., Sinnott, S., Sutton, B., Cincotta, R., Duncombe, G., Chua, J. and Peterson, M., 2017. Low first-trimester PAPP-A in IVF (fresh and frozenthawed) pregnancies, likely due to a biological cause. J Assist Reprod Genet.

Imudia, A.N., Awonuga, A.O., Doyle, J.O., Kaimal, A.J., Wright, D.L., Toth, T.L. and Styer, A.K., 2012. Peak serum estradiol level during controlled ovarian hyperstimulation is associated with increased risk of small for gestational age and preeclampsia in singleton pregnancies after in vitro fertilization. Fertil Steril. 97, 1374-1379.

Imudia, A.N., Awonuga, A.O., Kaimal, A.J., Wright, D.L., Styer, A.K. and Toth, T.L., 2013. Elective cryopreservation of all embryos with subsequent cryothaw embryo transfer in patients at risk for ovarian hyperstimulation syndrome reduces the risk of adverse obstetric outcomes: a preliminary study. Fertil Steril. 99, 168-173.

Isles, A.R. and Holland, A.J., 2005. Imprinted genes and mother-offspring interactions. Early Hum Dev. 81, 73-77.

Jackson, R.A., Gibson, K.A., Wu, Y.W. and Croughan, M.S., 2004. Perinatal outcomes in singletons following in vitro fertilization: a meta-analysis. Obstet Gynecol. 103, 551563.

Kaser, D.J., Melamed, A., Bormann, C.L., Myers, D.E., Missmer, S.A., Walsh, B.W., Racowsky, C. and Carusi, D.A., 2015. Cryopreserved embryo transfer is an independent risk factor for placenta accreta. Fertil Steril. 103, 1176-1184 e1172.

Liu, S., Kuang, Y., Wu, Y., Feng, Y., Lyu, Q., Wang, L., Sun, Y. and Sun, X., 2017. High oestradiol concentration after ovarian stimulation is associated with lower maternal serum beta-HCG concentration and neonatal birth weight. Reprod Biomed Online. 35, 189-196.

Messerlian, C. and Gaskins, A.J., 2017. Epidemiologic Approaches for Studying Assisted Reproductive Technologies: Design, Methods, Analysis and Interpretation. Curr Epidemiol Rep. 4, 124-132.

Miles, J.R., Farin, C.E., Rodriguez, K.F., Alexander, J.E. and Farin, P.W., 2004. Angiogenesis and morphometry of bovine placentas in late gestation from embryos produced in vivo or in vitro. Biol Reprod. 71, 1919-1926.

Miles, J.R., Farin, C.E., Rodriguez, K.F., Alexander, J.E. and Farin, P.W., 2005. Effects of embryo culture on angiogenesis and morphometry of bovine placentas during early gestation. Biol Reprod. 73, 663-671. 
Montagut, M., Santos-Ribeiro, S., De Vos, M., Polyzos, N.P., Drakopoulos, P., Mackens, S., Van De Vijver, A., Van Landuyt, L., Verheyen, G., Tournaye, H. and Blockeel, C., 2016. Frozen-thawed embryo transfers in natural cycles with spontaneous or induced ovulation: the search for the best protocol continues. Hum Reprod. 31, 2803-2810.

Moser, G. and Huppertz, B., 2017. Implantation and extravillous trophoblast invasion: From rare archival specimens to modern biobanking. Placenta. 56, 19-26.

Munch, E.M., Sparks, A.E., Zimmerman, M.B., Van Voorhis, B.J. and Duran, E.H., 2017. High FSH dosing is associated with reduced live birth rate in fresh but not subsequent frozen embryo transfers. Hum Reprod. 1-8.

Nakamura, Y., Yaguchi, C., Itoh, H., Sakamoto, R., Kimura, T., Furuta, N., Uchida, T., Tamura, N., Suzuki, K., Sumimoto, K., Matsuda, Y., Matsuura, T., Nishimura, M. and Kanayama, N., 2015. Morphologic characteristics of the placental basal plate in in vitro fertilization pregnancies: a possible association with the amount of bleeding in delivery. Hum Pathol. 46, 1171-1179.

Nathanielsz, P.W., 2006. Animal models that elucidate basic principles of the developmental origins of adult diseases. ILAR J. 47, 73-82.

Ouyang, F., Parker, M.G., Luo, Z.C., Wang, X., Zhang, H.J., Jiang, F., Gillman, M.W. and Zhang, J., 2016. Maternal BMI, gestational diabetes, and weight gain in relation to childhood obesity: The mediation effect of placental weight. Obesity (Silver Spring). 24, 938-946.

Ozgur, K., Bulut, H., Berkkanoglu, M., Humaidan, P. and Coetzee, K., 2018. Artificial cryopreserved embryo transfer cycle success depends on blastocyst developmental rate and progesterone timing. Reprod Biomed Online. 36, 269-276.

Papageorghiou, A.T., Kennedy, S.H., Salomon, L.J., Ohuma, E.O., Cheikh Ismail, L., Barros, F.C., Lambert, A., Carvalho, M., Jaffer, Y.A., Bertino, E., Gravett, M.G., Altman, D.G., Purwar, M., Noble, J.A., Pang, R., Victora, C.G., Bhutta, Z.A. and Villar, J., 2014. International standards for early fetal size and pregnancy dating based on ultrasound measurement of crown-rump length in the first trimester of pregnancy. Ultrasound Obstet Gynecol. 44, 641-648.

Papastefanou, I., Chrelias, C., Siristatidis, C., Kappou, D., Eleftheriades, M. and Kassanos, D., 2018. Placental volume at 11 to 14 gestational weeks in pregnancies complicated with fetal growth restriction and preeclampsia. Prenat Diagn.

Pinborg, A., Henningsen, A.A., Loft, A., Malchau, S.S., Forman, J. and Andersen, A.N., 2014. Large baby syndrome in singletons born after frozen embryo transfer (FET): is it due to maternal factors or the cryotechnique? Hum Reprod. 29, 618-627.

Prefumo, F., Fratelli, N., Soares, S.C. and Thilaganathan, B., 2007. Uterine artery Doppler velocimetry at 11-14 weeks in singleton pregnancies conceived by assisted reproductive technology. Ultrasound Obstet Gynecol. 29, 141-145.

Prefumo, F., Sebire, N.J. and Thilaganathan, B., 2004. Decreased endovascular trophoblast invasion in first trimester pregnancies with high-resistance uterine artery Doppler indices. Hum Reprod. 19, 206-209.

Ptak, G.E., D'agostino, A., Toschi, P., Fidanza, A., Zacchini, F., Czernik, M., Monaco, F. and Loi, P., 2013. Post-implantation mortality of in vitro produced embryos is associated with DNA methyltransferase 1 dysfunction in sheep placenta. Hum Reprod. 28, 298305.

Reynolds, L.P. and Caton, J.S., 2012. Role of the pre- and post-natal environment in developmental programming of health and productivity. Mol Cell Endocrinol. 354, 5459.

Rifouna, M.S., Reus, A.D., Koning, A.H., Van Der Spek, P.J., Exalto, N., Steegers, E.A. and Laven, J.S., 2014. First trimester trophoblast and placental bed vascular volume measurements in IVF or IVF/ICSI pregnancies. Hum Reprod. 29, 2644-2649.

Rizzo, G., Aiello, E., Pietrolucci, M.E. and Arduini, D., 2015. Placental volume and uterine artery doppler evaluation at $11+0$ to $13+6$ weeks of gestation in pregnancies conceived with in vitro fertilization: comparison between autologous and donor oocyte recipients. Ultrasound Obstet Gynecol. 
Rizzo, G., Aiello, E., Pietrolucci, M.E. and Arduini, D., 2016. Are There Differences in Placental Volume and Uterine Artery Doppler in Pregnancies Resulting From the Transfer of Fresh Versus Frozen-Thawed Embryos Through In Vitro Fertilization. Reprod Sci.

Rizzo, G., Capponi, A., Cavicchioni, O., Vendola, M. and Arduini, D., 2008. First trimester uterine Doppler and three-dimensional ultrasound placental volume calculation in predicting pre-eclampsia. Eur J Obstet Gynecol Reprod Biol. 138, 147-151.

Rousseau, T., Ferdynus, C., Quantin, C., Gouyon, J.B. and Sagot, P., 2008. [Liveborn birthweight of single and uncomplicated pregnancies between 28 and 42 weeks of gestation from Burgundy perinatal network]. J Gynecol Obstet Biol Reprod (Paris). 37, 589-596.

Salomon, L.J., 2011. [How to date pregnancy?]. J Gynecol Obstet Biol Reprod (Paris). 40, 726-733.

Schwartz, N., Sammel, M.D., Leite, R. and Parry, S., 2014. First-trimester placental ultrasound and maternal serum markers as predictors of small-for-gestational-age infants. Am J Obstet Gynecol. 211, 253 e251-258.

Sentilhes, L., Vayssiere, C., Deneux-Tharaux, C., Aya, A.G., Bayoumeu, F., Bonnet, M.P., Djoudi, R., Dolley, P., Dreyfus, M., Ducroux-Schouwey, C., Dupont, C., Francois, A., Gallot, D., Haumonte, J.B., Huissoud, C., Kayem, G., Keita, H., Langer, B., Mignon, A., Morel, O., Parant, O., Pelage, J.P., Phan, E., Rossignol, M., Tessier, V., Mercier, F.J. and Goffinet, F., 2016. Postpartum hemorrhage: guidelines for clinical practice from the French College of Gynaecologists and Obstetricians (CNGOF): in collaboration with the French Society of Anesthesiology and Intensive Care (SFAR). Eur J Obstet Gynecol Reprod Biol. 198, 12-21.

Shwarzman, P., Waintraub, A.Y., Frieger, M., Bashiri, A., Mazor, M. and Hershkovitz, R., 2013. Third-trimester abnormal uterine artery Doppler findings are associated with adverse pregnancy outcomes. J Ultrasound Med. 32, 2107-2113.

Sirikunalai, P., Wanapirak, C., Sirichotiyakul, S., Tongprasert, F., Srisupundit, K., Luewan, S., Traisrisilp, K. and Tongsong, T., 2016. Associations between maternal serum free beta human chorionic gonadotropin (beta-hCG) levels and adverse pregnancy outcomes. J Obstet Gynaecol. 36, 178-182.

Spijkers, S., Lens, J.W., Schats, R. and Lambalk, C.B., 2017. Fresh and Frozen-Thawed Embryo Transfer Compared to Natural Conception: Differences in Perinatal Outcome? Gynecol Obstet Invest.

Stampalija, T., Monasta, L., Di Martino, D.D., Quadrifoglio, M., Lo Bello, L., D'ottavio, G., Zullino, S., Mastroianni, C., Casati, D., Signorelli, V., Rosti, E., Cecotti, V., Ceccarello, M. and Ferrazzi, E., 2017. The association of first trimester uterine arteries Doppler velocimetry with different clinical phenotypes of hypertensive disorders of pregnancy: a longitudinal study. J Matern Fetal Neonatal Med. 1-9.

Sundheimer, L.W., Chan, J.L., Buttle, R., Dipentino, R., Muramoto, O., Castellano, K., Wang, E.T., Williams, J., 3rd and Pisarska, M.D., 2018. Mode of conception does not affect fetal or placental growth parameters or ratios in early gestation or at delivery. J Assist Reprod Genet.

Tan, M.Y., Poon, L.C., Rolnik, D.L., Syngelaki, A., De Paco Matallana, C., Akolekar, R., Cicero, S., Janga, D., Singh, M., Molina, F.S., Persico, N., Jani, J.C., Plasencia, W., Greco, E., Papaioannou, G., Wright, D. and Nicolaides, K.H., 2018. Prediction and prevention of small-for-gestational-age neonates: evidence from SPREE and ASPRE. Ultrasound Obstet Gynecol. 52, 52-59.

Tan, M.Y., Wright, D., Syngelaki, A., Akolekar, R., Cicero, S., Janga, D., Singh, M., Greco, E., Wright, A., Maclagan, K., Poon, L.C. and Nicolaides, K.H., 2018. Comparison of diagnostic accuracy of early screening for pre-eclampsia by NICE guidelines and a method combining maternal factors and biomarkers: results of SPREE. Ultrasound Obstet Gynecol. 51, 743-750. 
Thomopoulos, C., Tsioufis, C., Michalopoulou, H., Makris, T., Papademetriou, V. and Stefanadis, C., 2013. Assisted reproductive technology and pregnancy-related hypertensive complications: a systematic review. J Hum Hypertens. 27, 148-157.

Tul, N. and Novak-Antolic, Z., 2006. Serum PAPP-A levels at 10-14 weeks of gestation are altered in women after assisted conception. Prenat Diagn. 26, 1206-1211.

Turgal, M., Aydin, E. and Ozyuncu, O., 2017. Effect of micronized progesterone on fetalplacental volume in first-trimester threatened abortion. J Clin Ultrasound. 45, 14-19.

Vander Borght, M. and Wyns, C., 2018. Fertility and infertility: Definition and epidemiology. Clin Biochem.

Vrooman, L.A. and Bartolomei, M.S., 2017. Can assisted reproductive technologies cause adult-onset disease? Evidence from human and mouse. Reprod Toxicol. 68, 72-84.

Wegrzyn, P., Faro, C., Falcon, O., Peralta, C.F. and Nicolaides, K.H., 2005. Placental volume measured by three-dimensional ultrasound at 11 to $13+6$ weeks of gestation: relation to chromosomal defects. Ultrasound Obstet Gynecol. 26, 28-32.

Weinerman, R. and Mainigi, M., 2014. Why we should transfer frozen instead of fresh embryos: the translational rationale. Fertil Steril. 102, 10-18.

Yding Andersen, C. and Vilbour Andersen, K., 2014. Improving the luteal phase after ovarian stimulation: reviewing new options. Reprod Biomed Online. 28, 552-559.

Yovich, J.L., Conceicao, J.L., Stanger, J.D., Hinchliffe, P.M. and Keane, K.N., 2015. Midluteal serum progesterone concentrations govern implantation rates for cryopreserved embryo transfers conducted under hormone replacement. Reprod Biomed Online. 31, 180-191.

Yucel, B., Gedikbasi, A., Dundar, O., Olgac, Y., Yildirim, D., Yildirim, G. and Polat, I., 2016. The utility of first trimester uterine artery Doppler, placental volume and PAPP-A levels alone and in combination to predict preeclampsia. Pregnancy Hypertens. 6, 269-273.

Zhabin, S.G., Gorin, V.S. and Judin, N.S., 2003. Review: immunomodulatory activity of pregnancy-associated plasma protein-A. J Clin Lab Immunol. 52, 41-50.

Zhang, Y., Zhang, Y.L., Feng, C., Wu, Y.T., Liu, A.X., Sheng, J.Z., Cai, J. and Huang, H.F., 2008. Comparative proteomic analysis of human placenta derived from assisted reproductive technology. Proteomics. 8, 4344-4356.

Zhu, X.L., Wang, J., Jiang, R.Z. and Teng, Y.C., 2015. Pulsatility index in combination with biomarkers or mean arterial pressure for the prediction of pre-eclampsia: Systematic literature review and meta-analysis. Ann Med. 47, 414-422. 


\section{FIGURE LEGENDS}

Figure 1. Comparison of crown-rump length (A), placental volume (B), uterine artery pulsatility index (C) and birth weight (D) between groups. Each box represents the interquartile range (IQR). Lines inside the boxes are the median. Whiskers represent the $10^{\text {th }}$ and $90^{\text {th }}$ percentiles. Crosses represent the mean. $P$ is the result from multivariate analyses. All variables associated with the dependent variable with a P-value below 0.2 in bivariate analyses were included in the multiple regression analysis among maternal age, height, weight, body mass index (BMI), parity, smoking habits, gestational age and new-born's sex. ns: non-significant. Fresh ET: Fresh Embryo Transfer, FET: Frozen-thawed Embryo Transfer.

Figure 2. ART is responsible for altered trophoblastic invasion, either decreased after in vitro fertilization (IVF) with fresh embryo transfer (Fresh ET) or exacerbated after frozen-thawed embryo transfer (FET).

In most cases, the placenta is able to compensate for original injury throughout pregnancy, which results in a healthy new-born. However, if compensation is overwhelmed, the consequences could be adverse obstetrical and neonatal outcomes. The Developmental Origin of Health and Diseases (DOHaD) concept states that intra-uterine events can affect future life.

LGA: large for gestational age, $\mathrm{PI}$ : uterine artery pulsatility index, $\mathrm{PPH}$ : post-partum haemorrhage, PV: placental volume, SGA: small for gestational age

\footnotetext{
Supplemental Figure 1. Correlations between log PV and $\beta-h C G$ (A) PAPP-A (B), uterine artery PI (C) in the whole population. Correlation between log PV and PAPP-A in the FET group (D).

PI: pulsatility index, PV: placental volume at the first-trimester ultrasound.
} 
Supplemental Figure 2. Correlation between birth weight and first trimester PAPP-A

(A) and log PV adjusted for gestational age (B) in the whole population.

PV: placental volume at the first-trimester ultrasound. 
A

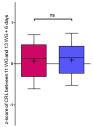

Protet ret

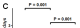

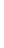

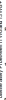

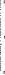

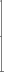

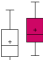

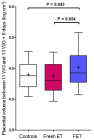

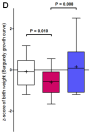




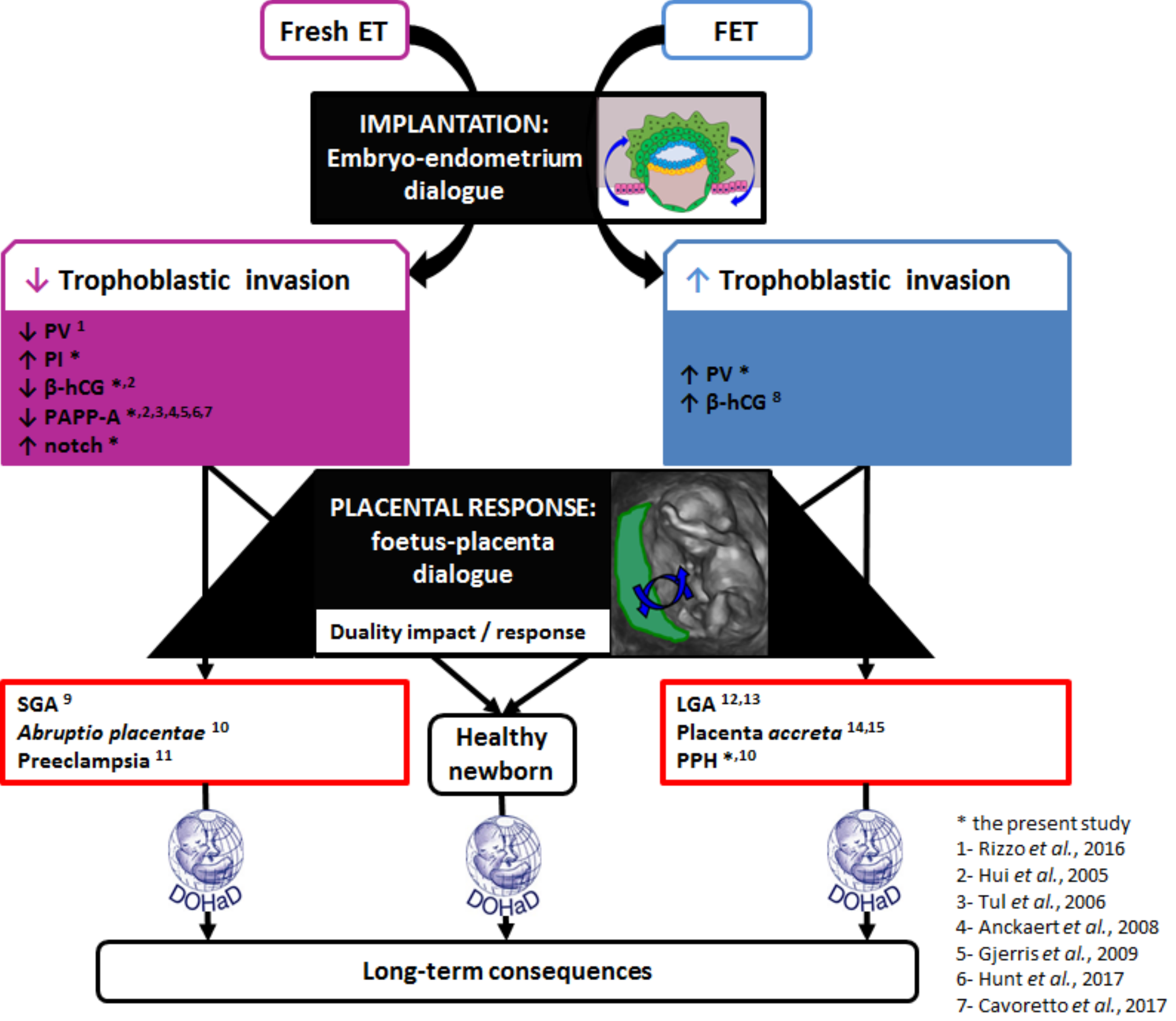


Table 1 Population Characteristics.

\begin{tabular}{lcccccc}
\hline & $\begin{array}{c}\text { Controls } \\
(\mathbf{n}=\mathbf{1 6 8})\end{array}$ & $\begin{array}{c}\text { Fresh ET } \\
(\mathbf{n}=\mathbf{6 0})\end{array}$ & $\begin{array}{c}\text { FET } \\
(\mathbf{n}=\mathbf{2 4})\end{array}$ & $\begin{array}{c}\mathbf{P} \\
\text { (global test) }\end{array}$ & $\begin{array}{c}\mathbf{P} \\
\text { (Fresh ET vs. C) }\end{array}$ & $\begin{array}{c}\mathbf{P} \\
\text { (FET vs. C) }\end{array}$ \\
\hline (Fresh ET vs. FET)
\end{tabular}

Quantitative data: mean \pm SD, qualitative data: $n(\%)$

ART: Assisted reproductive technologies, BMI: Body Mass Index, C: Controls, FET: Frozen-thawed Embryo Transfer, Fresh ET: Fresh Embryo Transfer,

PCOS: PolyCystic Ovary Syndrome

$P$ is the result from univariate analyses. $P<0.05$ in bold 
Table 2 First-trimester data.

\begin{tabular}{|c|c|c|c|c|c|c|c|}
\hline & $\begin{array}{l}\text { Controls } \\
(n=168)\end{array}$ & $\begin{array}{l}\text { Fresh ET } \\
(n=60)\end{array}$ & $\begin{array}{c}\text { FET } \\
(n=24)\end{array}$ & $\begin{array}{c}\mathrm{P} \\
\text { (global test) }\end{array}$ & $\begin{array}{c}\text { P } \\
\text { (Fresh ET vs. C) }\end{array}$ & $\begin{array}{c}\mathrm{P} \\
\text { (FET vs. C) }\end{array}$ & $\begin{array}{c}\text { P } \\
\text { (Fresh ET vs. FET) }\end{array}$ \\
\hline \multicolumn{8}{|l|}{ First-trimester ultrasound } \\
\hline maximal uterine artery $\mathrm{PI}$ & $1.52 \pm 0.59$ & $1.86 \pm 0.64$ & $1.26 \pm 0.44$ & $<0.001$ & 0.001 & 0.112 & 0.001 \\
\hline presence of diastolic & $53 / 163(32.5)$ & $30 / 54(55.6)$ & $5 / 17(29.4)$ & 0.008 & 0.003 & 0.794 & 0.060 \\
\hline \multicolumn{8}{|l|}{ notching } \\
\hline placental volume $\left(\log \mathrm{cm}^{3}\right)$ & $4.40 \pm 0.283$ & $4.38 \pm 0.37$ & $4.52 \pm 0.39$ & 0.068 & & & \\
\hline z-score of CRL & 0 & $0.07 \pm 0.53$ & $0.09 \pm 0.48$ & 0.186 & & & \\
\hline PAPP-A (MoM) & $1.12 \pm 0.60$ & $0.91 \pm 0.48$ & $1.02 \pm 0.64$ & 0.049 & 0.016 & 0.457 & 0.407 \\
\hline$\beta$-hCG (MoM) & $1.21 \pm 0.67$ & $0.92 \pm 0.47$ & $1.19 \pm 0.53$ & 0.007 & 0.002 & 0.902 & 0.067 \\
\hline
\end{tabular}

Quantitative data: mean \pm SD, qualitative data: $n(\%)$

C: Controls, FET: Frozen-thawed Embryo Transfer, Fresh ET: Fresh Embryo Transfer, PI: placental index, $\mathrm{P}$ is the result from univariate analyses, P<0.05 in bold 
Table 3 Obstetrical and neonatal outcomes.

\begin{tabular}{|c|c|c|c|c|}
\hline & $\begin{array}{l}\text { Controls } \\
(n=168)\end{array}$ & $\begin{array}{c}\text { Fresh ET } \\
(n=60)\end{array}$ & $\begin{array}{c}\text { FET } \\
(n=24)\end{array}$ & $\begin{array}{c}\mathbf{P} \\
\text { (global test) }\end{array}$ \\
\hline \multicolumn{5}{|l|}{ Obstetric outcomes } \\
\hline severe preeclampsia & $4 / 156(2.6)$ & 2/54 (3.7) & $0 / 21(0)$ & 0.803 \\
\hline preterm labour & $15 / 156(9.6)$ & 6/54 (11.1) & $2 / 21(9.5)$ & 0.939 \\
\hline gestational hypertension & $0 / 156(0)$ & $0 / 54(0)$ & $1 / 21(4.8)$ & 0.091 \\
\hline gestational diabetes & 22/156 (14.1) & 6/54 (11.1) & $1 / 21(4.8)$ & 0.542 \\
\hline premature preterm rupture of membranes & $0 / 156(0)$ & $1 / 54(1.9)$ & $0 / 21(0)$ & 0.325 \\
\hline chorioamniotitis & $4 / 156(2.6)$ & $2 / 54(3.7)$ & $0 / 21(0)$ & 0.803 \\
\hline abruptio placentae & $1 / 156(0.6)$ & $1 / 54(1.9)$ & $0 / 21(0)$ & 0.545 \\
\hline \multicolumn{5}{|l|}{ Delivery } \\
\hline gestational age (WG) & $39.5 \pm 2.5$ & $39.0 \pm 2.7$ & $40.0 \pm 1.4$ & 0.060 \\
\hline premature birth $<37 \mathrm{WG}$ & $8 / 156(5.1)$ & $3(5.0)$ & $1(4.2)$ & 1 \\
\hline premature birth $<34 \mathrm{WG}$ & 3/156 (1.9) & $1(1.7)$ & $0(0)$ & 1 \\
\hline labour induction & $42 / 156(26.9)$ & $18 / 54(33.3)$ & $8 / 21(38.1)$ & 0.443 \\
\hline post-partum haemorrhage & $4 / 156(2.6)$ & $1 / 54(1.9)$ & $8 / 21(38.1)$ & $<0.0001$ \\
\hline instrumental delivery & $22 / 156(14.1)$ & $20 / 57(35.1)$ & $6(26.1)$ & 0.003 \\
\hline caesarean section & $30 / 156(19.2)$ & 7/59 (11.9) & $6(25.0)$ & 0.270 \\
\hline Birth weight (grams) & $3281.8 \pm 549.7$ & $3040.8 \pm 598.1$ & $3526.5 \pm 540.8$ & $<0.001$ \\
\hline birth weight $<10^{\text {th }}$ centile (SGA) & $11 / 142(7.8)$ & 10/52 (19.2) & $1 / 18(5.6)$ & 0.076 \\
\hline birth weight $>90^{\text {th }}$ centile $(\mathrm{LGA})$ & $12 / 142(8.5)$ & 2/52 (3.9) & $2 / 18(11.1)$ & 0.368 \\
\hline Birth weight (z-score) & $-0.074 \pm 0.92$ & $-0.60 \pm 0.96$ & $0.15 \pm 1.27$ & 0.002 \\
\hline
\end{tabular}




\begin{tabular}{|c|c|c|c|c|}
\hline APGAR score at 5' & $9.73 \pm 1.19$ & $9.73 \pm 1.43$ & $9.68 \pm 1.43$ & 0.982 \\
\hline Respiratory distress & $12 / 156(7.7)$ & $3 / 54(5.6)$ & $0 / 21(0)$ & 0.477 \\
\hline
\end{tabular}

Quantitative data: mean \pm SD, qualitative data: $n(\%)$

C: Controls, FET: Frozen-thawed Embryo Transfer, Fresh ET: Fresh Embryo Transfer, LGA: Large for Gestational Age, SGA: Small for Gestational Age, P is the result from univariate analyses, $\mathrm{P}<0.05$ in bold 